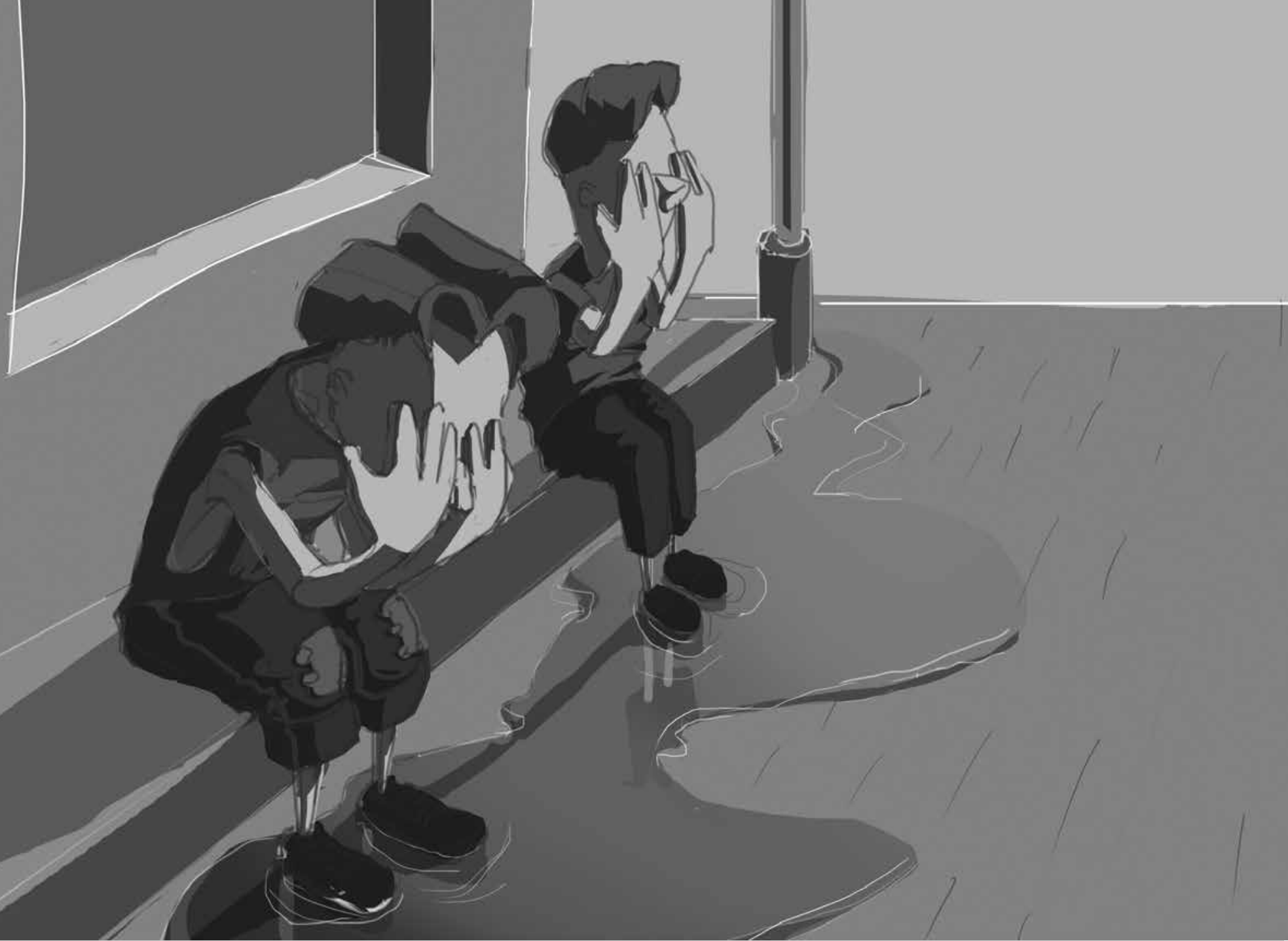

\title{
Universo simbólico y pedagogía deconstructiva: un camino para el empoderamiento y la construcción de autonomía ${ }^{1}$
}

Symbolic universe and deconstructive pedagogics: a way to empowering and autonomy construction

Universo simbólico e pedagogia desconstrutiva: um caminho par o empoderamento e a construção da autonomia

1. Trabajo premiado en el Premio a la Investigación e Innovación Educativa y Pedagógica, 2013. SED. 
Jairo Guillermo Hoyos Gutiérrez²
2. Magíster en Investigación Social Interdisciplinaria, Universidad Distrital Francisco José de Caldas. Docente del Colegio Liceo Nacional Antonia Santos IED. Correo electrónico: monotinto@yahoo.

Fecha de recepción: 29 de octubre de 2014 / fecha de aprobación: 4 de febrero de 2015

\section{Resumen}

Este trabajo pretende dar cuenta de una experiencia pedagógica centrada en la exploración, análisis crítico y transformación de los universos simbólicos de los y las estudiantes. La descripción e interpretación de la realidad en los llamados países "tercermundistas" parte de una mirada y una lógica etnocentrista que subordina a estos países, dando lugar a la construcción simbólica de subjetividades subalternas. En ese sentido, la intervención pretende develar la arbitrariedad cultural subyacente en la mirada que hemos construido de nosotros mismos, del otro y del mundo y posibilitar caminos para deconstruirla.

Palabras clave: Pedagogía, universo simbólico, deconstrucción, representaciones sociales, empoderamiento, autonomía.

\section{Summary}

The aim of this paper is to present a pedagogic experience centered in the exploration, critical analysis, and transformation of symbolic universes of students. The description and interpretation of reality in the so called "third world countries" comes from a ethnocentric view and logic, which subordinates these countries, producing a symbolic construction of subaltern subjectivities. In this sense, the intervention aims at revealing the cultural arbitrariness underlying the view we have constructed of ourselves, of the other, and of the world itself, and at opening ways to deconstruct it.

Keywords: Pedagogics, symbolic universe, deconstruction, social representations, empowerment, autonomy.

\section{Resumo}

O objetivo deste trabalho é mostrar uma experiência pedagógica centrada na exploração, análise crítica e transformação dos universos simbólicos dos e das estudantes. A descrição e interpretação da realidade nos chamados países "terceiro-mundistas" parte de um olhar e de uma lógica etnocentrista e subordinante destes países, que permite a construção simbólica de subjetividades subalternas. Em tal sentido a intervenção pretende revelar a arbitrariedade cultural subjacente no olhar que temos construído de nós mesmos, do outro e do mundo, e possibilitar caminhos para sua desconstrução.

Palavras chave: Pedagogia, universo simbólico, desconstrução, representações sociais, empoderamento, autonomia. 


\section{Introducción}

- 1 presente trabajo parte de la intención de intervenir frente — a problemas presentes en el contexto educativo, que están ligados a los universos simbólicos de los y las estudiantes y que dificultan el desarrollo de procesos cognitivos, comunicativos y relacionales. Algunos de estos problemas tienen que ver con el desinterés de los estudiantes por los procesos académicos, los bajos niveles de lectura y comprensión lectora, los escasos niveles de participación en las clases, el temor a hablar en público, la inseguridad en sí mismos, el miedo a equivocarse, la baja autoestima, el temor al ridículo o al aislamiento, la burla entre pares y las relaciones de discriminación, intolerancia e intimidación en la convivencia escolar.

Una exploración inicial, permitió que afloraran algunos elementos que insinuaban la existencia de una autopercepción desvalorizada, la ubicación del sujeto dentro de una estructura de subalternidad y una falta de credibilidad en sí mismos y en sus capacidades. Ello llevo a la formulación de una pregunta inicial que orienta el desarrollo de la indagación: ¿cómo está constituido y cómo se construye el universo simbólico de los estudiantes y qué papel juega la institución escolar en esta construcción?

\section{Buscando caminos}

En los procesos educativos se observa que una buena parte de los estudiantes llegan a la escuela con actitudes, valores, autopercepciones y expectativas bastante bajas y que a pesar de ir avanzando en los grados de escolaridad, estas dificultades generalmente se mantienen o incluso, se afianzan. Aunque a primera vista estas dificultades parecen ser características individuales y particulares de cada quien -uno "es" tímido, otro distraído, otro más permanece triste, otro avergonzado, otro agresivo, otros se sienten intimidados, etc.- una mirada de conjunto permite identificar una problemática común que se podría caracterizar como des empoderamiento y baja valoración de sí mismo.

Partimos entonces de la interpretación de que el problema no está solo afuera, en lo social, sino también adentro, en la interioridad: cómo nos vemos, cómo nos percibimos a nosotros mismos, cómo nos valoramos o subvaloramos o sobrevaloramos, cada quien con una subjetividad, una descripción de sí mismo y del mundo, construida por el camino, sin saberlo, sin conciencia de ella. Cada quien un mundo, pero en el fondo, un mundo construido con elementos comunes, enmarcados en el contexto de una estructura socio cultural y un universo simbólico construido desde una lógica eurocentrista que comparte valoraciones, jerarquías, acuerdos, patrones de comportamiento, heteronomía, estereotipos, prejuicios, creencias, intolerancias, discriminaciones y autodiscriminaciones. Todos estos elementos hacen parte de un universo simbólico interiorizado que funciona como mecanismo de reproducción y de legitimación de la desigualdad social, al cual habría que acceder para resignificarlo.

\section{Tendiendo puentes}

Frente a estos problemas identificados, se pretende intervenir en el sentido de transformar el aula de clase en un espacio amable, respetuoso, armónico, interesante, participativo, crítico y reflexivo, que permita el empoderamiento de las personas, el fortalecimiento de la autoestima, la ampliación de sus sensibilidades y expectativas, y el ejercicio de sus derechos y libertades, para que los individuos puedan redefinirse como protagonistas de su propia historia y asumir, de manera consciente, autónoma y responsable su proyecto de vida.

La intención es implementar un modelo de intervención que haga posible la identificación, el análisis y la deconstrucción de algunos elementos clave de los universos simbólicos y de los imaginarios y representaciones sociales de carácter dogmático, reduccionista y devaluador que portan los estudiantes, y buscar estrategias que posibiliten una resignificacion propositiva e intencionada que afecte, no solo los procesos de enseñanza aprendizaje, sino la experiencia vital de la persona, la construcción de su subjetividad y la ampliación de sus perspectivas de vida.

Partimos de suponer que, aunque los problemas señalados han sido construidos inicialmente en el contexto familiar y social, son también en parte, construidos en el contexto escolar y que, generar una transformación, pasa por la indagación de ese universo simbólico. ¿Qué nociones, representaciones sociales, ideas-fuerza, imágenes, constituyen los entramados simbólicos de los estudiantes?, ¿están relacionados con la exclusión social y la marginalización?, ¿'son entramados simbólicos subalternos?, ¿Cómo ha construido cada quien la imagen de sí mismo?, ¿es posible transformarla?, ¿existen elementos socioculturales que intervienen en ella y la constituyen en tendencia?, ¿el contexto escolar ayuda a superar estos problemas o por el contario los reproduce y afianza? 


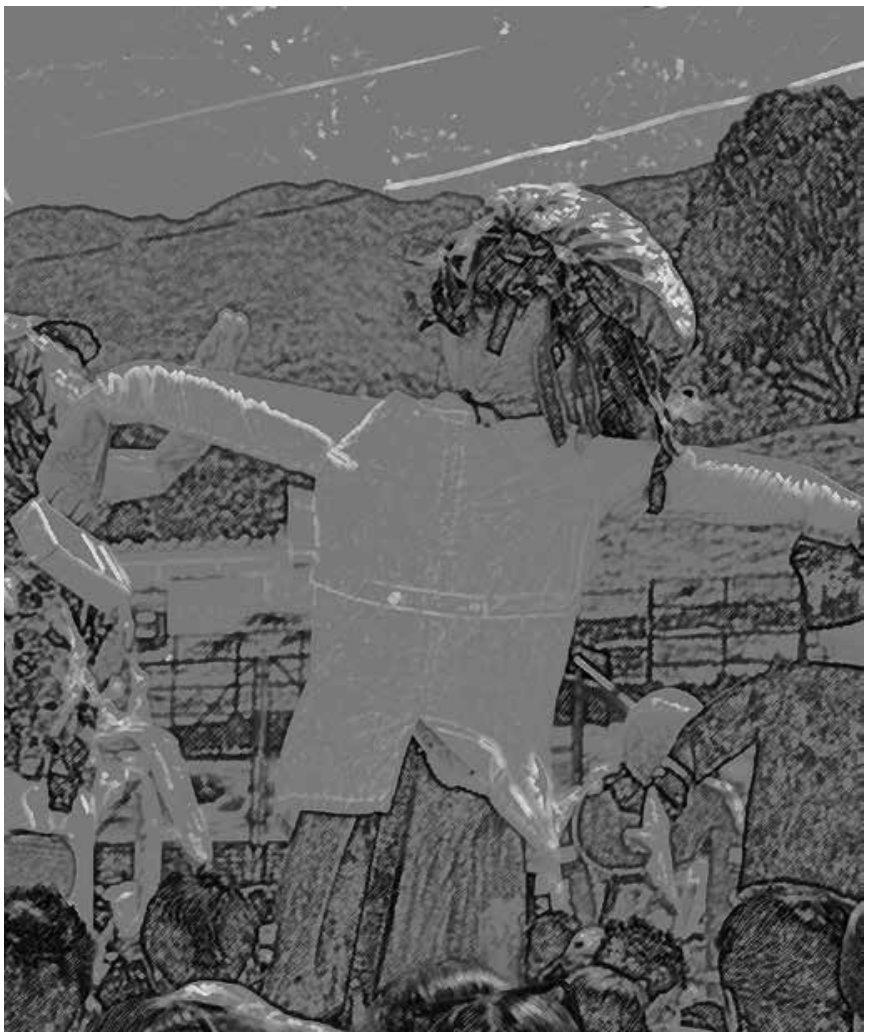

A partir de estas preguntas se buscó la identificación de elementos explicativos, desde una perspectiva interdisciplinaria, que abordaremos retomando elementos desde la sociología de Bourdieu, desde la psicología social con la teoría de las representaciones sociales y desde la filosofía con el planteamiento de la deconstrucción de Derrida.

Un primer concepto clave es el de la arbitrariedad cultural. Afirma Bourdieu que:

"La arbitrariedad cultural que las relaciones de fuerza entre las clases o los grupos constitutivos de esta formación social colocan en posición dominante en el sistema de arbitrariedades culturales, es aquella que expresa más completamente, aunque casi siempre de forma mediata, los intereses objetivos (materiales y simbólicos) de los grupos o clases dominantes" (Bourdieu, 1972).

En otras palabras, la cultura de la clase dominante es seleccionada arbitrariamente como sistema simbólico y legitimado como tal y frente a él, la cultura de las otras clases sociales aparece devaluada. Es por esto por lo que Bourdieu concluye que el sis- tema educativo cumple la función de reproducción simbólica de las estructuras sociales. Esta arbitrariedad cultural es encubierta, es decir, disimulada, por medio de la legitimación.

En ese sentido, el origen de clase de nuestros estudiantes sectores populares, clases medias- establece un determinado nivel de capital lingüístico y de capital cultural que está muy distante del que la escuela utiliza -capital lingüístico y cultural de las clases dominantes- por lo que, de entrada, nuestros estudiantes están en desventaja frente a lo que el sistema educativo requiere.

$\mathrm{El}$ segundo concepto que se retoma tiene que ver con la necesidad de tener herramientas metodológicas para explorar el universo simbólico que portan los estudiantes. En ese sentido, las representaciones sociales pueden operar como puentes de acceso a esos caudales simbólicos de los que tanto estudiantes como docentes, somos portadores, en la medida en que constituyen una forma de visión global y unitaria "del mundo que permite a un individuo o grupo, conferir sentido a sus conductas, entender la realidad mediante su propio sistema de referencia y adaptar y definir de este modo un lugar para sî" (Abric, 2001). La propuesta es entonces intervenir sobre estos elementos simbólicos que contribuyen a construir la desvalorización del sujeto y el aprendizaje de la desesperanza, en primer lugar, develándolos, desestructurándolos, evidenciando su arbitrariedad y los mecanismos de autoexclusión que están implícitos en ellos. Cabe anotar que esta experiencia se enfocó solamente en las representaciones sociales de los y las estudiantes.

Este proceso de develación, de romper certezas interiorizadas, podríamos denominarlo pedagogía deconstructiva, tomando prestado el concepto derridiano. La deconstrucción pretende descomponer la estructura de lo simbólico, del lenguaje, sea un texto, una frase, una palabra, un adjetivo, un concepto, un dicho, para descubrir las diferentes significaciones que tiene y sus connotaciones relativas, históricas y transitorias, evidenciando no solo lo dicho, sino también, lo no dicho, sus implícitos, sus implicaciones, sus ocultamientos, sus relaciones; en fin, la arbitrariedad cultural sobre la que estos símbolos están construidos, revelando que lo que se considera evidente, está lejos de serlo. Realizar este proceso requiere un nivel de distanciamiento de la mirada cotidiana, de la lógica del día a día, una pedagogía de la sospecha, como diría Nietzsche. Mirar con extrañeza, lo conocido.

En ese orden de ideas, el universo simbólico, la arbitrariedad cultural, las representaciones sociales y el planteamiento deconstructivo de Derrida, constituyen el marco teórico desde el que se plantea esta propuesta de intervención. 


\section{Explorando lo invisible}

Durante la exploración se acudió al uso de herramientas cualitativas y cuantitativas. Emergió entonces un caudal de violencia simbólica hecha cuerpo: en su mayoría se sentían torpes, poco inteligentes, sin ninguna cualidad particularmente destacable, poco atractivos y atractivas, poco queridos, poco merecedores de una vida mejor, más enriquecedora, más amable. Los resultados de la aplicación de estas herramientas reiteraron la existencia de autoestimas bajas en más de la mitad de los estudiantes. Intervenir frente a eso se convirtió en objetivo prioritario. Tomando el aula como laboratorio, se comenzaron a ensayar estrategias, que a veces lograban avances, a veces no; andando por intuición iban apareciendo pistas. En este camino los diarios de campo fueron una herramienta fundamental.

Explorar el terreno de las representaciones sociales, terreno aparentemente intangible, resulto no ser tan etéreo como parecía, había "terreno firme". Como lo afirma Levy Strauus en la introducción del libro de Mauss (1979) "los símbolos son más reales que aquello que simbolizan” (Mauss, 1979).

Sin embargo, a pesar de su firmeza, el hecho de evidenciar la arbitrariedad cultural que subyace en esas representaciones sociales constituye ya un paso en el proceso deconstructivo. Se fue configurando un modelo pedagógico para intervenir en el universo simbólico, bajo la premisa de que existen elementos que, por una parte, construyen relaciones de subalternidad frente al otro y por otra, al ser constructos autorreferentes, subordinan, devalúan y descalifican al sujeto en la percepción que éste tiene de sí mismo. Tanto la percepción del sí mismo como la percepción del otro, posicionan al sujeto dentro de un entramado simbólico que le otorga sentido y significado, le asigna un papel en el mundo, un lugar en el. La intención es entonces, encontrar ese lugar, ponerlo en cuestión, reflexionarlo, relativizarlo y, de ser necesario, reconstruirlo desde la subjetividad de cada quien. Buscar esta transformación implicó realizar cambios en el encuadre de la clase a varios niveles.

\section{Cambiando el escenario}

En esta fase se desarrolló la reflexión en cuanto a las transformaciones necesarias para reconfigurar y resignificar el espacio y el encuadre de la clase, de manera que posibilitara un clima relacional diferente. Como la intención es sistematizar la experiencia se hablará de ella de una manera que puede ser bastante esquemática, pero que permite sintetizar su desarrollo.
Se plantearon como requerimientos básicos hacer transformaciones en términos de los niveles proxémico, relacional, comunicativo-pedagógico y epistemológico al interior del aula.

A. En el nivel proxémico: En términos del espacio, se cambió la disposición cuadriculada del salón -simetría para ordenar y vigilar, diría Michel Foucault- por una disposición que permitiera la circularidad, lo que reconfigura por completo el espacio, puesto que, por un lado, dinamiza y hace posible la circulación fluida de las miradas, los discursos, los gestos y las discusiones, ampliando la interrelación entre pares y por otro, minimiza o reduce la presencia del docente como centro de poder, autoridad y saber, poniendo en juego también los poderes y saberes de los estudiantes. Aunque puede parecer un cambio de poca importancia, la transformación en la percepción del sujeto cambia de manera significativa, porque altera la sensación que la persona tiene de su espacio físico y social y de su intimidad personal. Una cosa es estar en un lugar asignado dentro de un plano cartesiano lo cual produce la sensación de aislamiento y otra muy

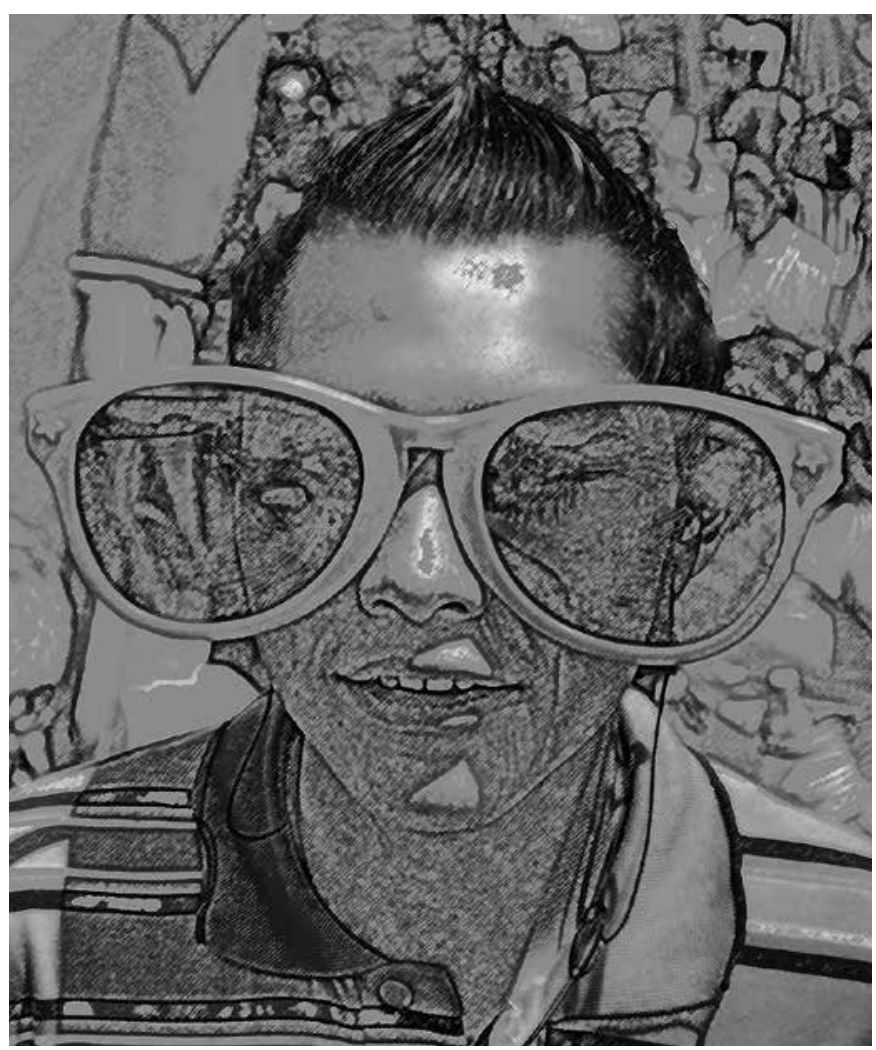




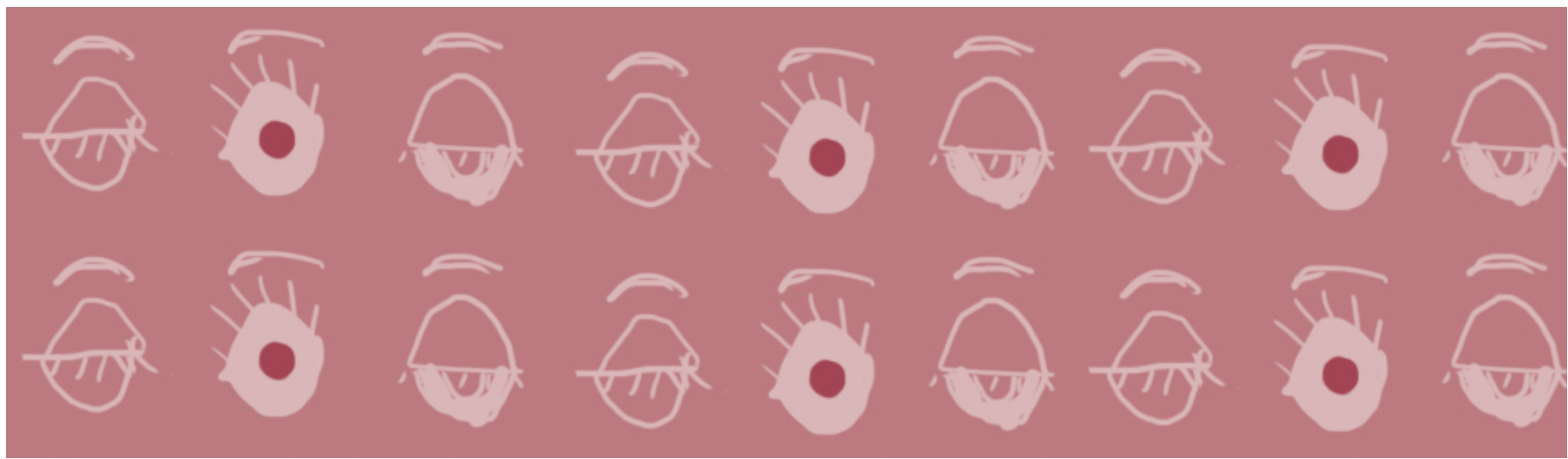

diferente hacer parte de una estructura circular que permite la integración dentro de un colectivo. Para decirlo de una manera un poco gráfica, en el primer caso al mirar hacia el frente se ven nucas, en el segundo, rostros. La diferencia es abismal pero invisible, así son los símbolos.

B. En el nivel relacional: En términos de reconfiguración de las relaciones de poder y en coherencia con el punto anterior, se plantea la horizontalidad como regla de juego básica para la clase. Aunque usualmente existen tensiones y relaciones de poder intimidatorias por parte de algunos estudiantes al interior de los grupos, - a veces también entre docentes y estudiantes- la reflexión, el posicionamiento y la explicitación por parte del docente de la horizontalidad como marco de referencia de la clase, permite gradualmente la minimización o neutralización de los estudiantes que se consideran con más poder dentro del grupo, evitando la discriminación y la intimidación. En este sentido, ha sido útil la realización de talleres sobre Derechos Humanos, modelos de comunicación asertiva, análisis de las motivaciones y presupuestos de las personalidades intimidadoras, empoderamiento individual y grupal y respeto a la diversidad.

El logro del equilibrio en las relaciones de poder al interior del grupo es un proceso en el que se van reconfigurando las tensiones, en la medida en que el grupo logra gradualmente empoderarse e ir deslegitimando las actitudes intimidadoras y discriminatorias de sus pares.

C. En el nivel comunicativo y pedagógico: se explicitó la intencionalidad particular que tiene esta clase: pasar de la ingenuidad a la toma de posición, del silencio a la palabra apropiada; del desconocimiento al autoconocimiento; de la obediencia a la iniciativa; de la repetición de esquemas al pensamiento crítico y reflexivo; de la desapropiación de la propia vida a asumir el cien por ciento de la responsabilidad de lo que pase en ella; de la victimización al protagonismo; de la subvaloración y la subalternidad al empoderamiento; de la heteronomía a la autonomía; del individualismo y la competencia a la solidaridad.

D. En el nivel epistemológico: se hizo explícito para los grupos cuáles son los puntos de partida o los supuestos básicos de la clase. a. El conocimiento es una construcción social y en ese sentido, la opinión, el diálogo, el debate y la participación de todos y todas es la materia prima de la clase y permite desarrollar la capacidad argumentativa, comunicativa y la expresión oral. b.Ningún proceso educativo parte de cero, cada quien tiene algo para aportar. c.Nadie nació aprendido, la equivocación enriquece y hace parte del proceso de aprendizaje. d. El conflicto y la duda son imprescindibles para cualquier proceso de conocimiento y crecimiento. e. Todos los seres humanos nacen libres e iguales en dignidad y derechos, nadie está por encima de nadie.

F. La ignorancia es un problema de llenura, no de carencia.

\section{Puesta en escena}

Después de varios ensayos se adoptó como metodología un proceso de intervención que esquemáticamente podría definirse en tres pasos:

1. Exploración de representaciones sociales: Tomar el concepto, el tema, la frase, el símbolo, la imagen; es decir, el objeto y aplicar un instrumento que haga aflorar la representación social que el grupo tiene de él. Generalmente se aplica a través de una pregunta o una afirmación incompleta en la que se pide al estudiante que complete el o los términos que faltan. También 
se ha trabajado por medio de identificación de redes semánticas y ejercicios de libre asociación. Luego de esto se van recogiendo los resultados para hacer el consolidado e identificar tendencias, las que, generalmente son mayoritarias y/o unificadas.

\section{Con base en la representación encontrada se formulan preguntas que} llevan a su relativización. Se trata de interrogar estas representaciones, buscar y evidenciar sus contradicciones, sus consecuencias, sus implícitos, su lógica interna, identificar sus fuentes, sus caminos de construcción y circulación y la arbitrariedad cultural implícita en ellos.

Estas representaciones sociales están legitimadas en el pensamiento social y en el sentido común a través de procesos de normalización y naturalización. Se plantean entonces situaciones hipotéticas con los resultados obtenidos para ver sus consecuencias, a qué llevaría, qué pasaría si fuera así para todos los casos, qué desprendimientos lógicos se derivan de allí, qué otras acepciones o sentidos tienen esas palabras, cómo se pueden desbaratar, cuál es su etimología y qué sentido ocultan; se llevan a situaciones límite que ponen en evidencia la contradicción, la fisura, o el quiebre de la representación. Esto es lo que hemos llamado el proceso propiamente deconstructivo. Generalmente, este proceso produce choques o disonancias cognitivas _ “insight” en términos psicoanalíticos- que desestabilizan, perturban, desconciertan y confunden momentáneamente, porque se ha producido una fractura en el universo simbólico del individuo y del grupo.

3. El tercer paso consiste en hacer una resignificación intencionada de la representación, haciendo planteamientos propositivos que buscan un nuevo sentido, desde lo que el grupo proponga, discuta y considere como deseable, buscando consensos, y se discute acerca de las proyecciones que tiene el nuevo sentido o constructo que se ha hecho y se evalúa qué dificultades, riesgos y límites tiene, para funcionar en el mundo cotidiano.

Quizá, lo más indicado sea ilustrar este proceso con ejemplos, narrando algunos de los ejercicios desarrollados en clase. Tomemos como ejemplo el concepto de clase social. Se le preguntó a un curso de grado octavo a qué clase social pertenecían, a lo cual respondieron que a la clase baja. Se mencionaron algunas características de la clase social baja y alta y se tomaron estos términos como elemento inicial de indagación y reflexión. Se dividió el tablero en dos partes, una con la palabra bajo y otra con la palabra alto y se les pidió que buscaran el significado de las dos palabras junto con sus sinónimos y todo lo que salió de allí, fue recogido en el siguiente cuadro comparativo:

\section{CLASE SOCIAL}

\section{BAJA}

Bajo: adjetivo. De poca altura o situado a poca distancia del suelo.

Sinónimos*:

Pequeño, diminuto, humilde, sencillo,

inferior, plebeyo, apocado, apagado, descolorido, mortecino, tênue, débil indigno, innoble, trivial, abyecto, despreciable, ruin, mezquino.

* Fuente: http://que-significa.com/sinonimos y http://www.wordreference.com/sinonimos

Luego, se pidió a los y las estudiantes que leyeran el cuadro de conjunto y que reflexionaran e hicieran las observaciones que les parecieran interesantes. Se plantearon preguntas como ¿tiene relación la estatura de las personas con su pertenencia a una clase social? ¿Si no es así, por qué se usa una palabra que designa estatura para referirse a la capacidad económica?, ¿cuál es la relación simbólica que se está estableciendo?, ¿hay precisión y pertinencia en el uso del término o es una arbitrariedad?, ¿que se pretende con esto? ¿Qué influencia puede tener esto en las personas?, ¿configura de alguna manera la forma de mirarse a sí mismo y de mirar el mundo?, ¿cómo?, ¿verían ustedes el mundo de la misma forma si se sintieran pertenecientes a la clase social alta?

Ejercicios como este, realizados alrededor de la deconstrucción de elementos del universo simbólico, permiten evidenciar, develar, poner al descubierto los mecanismos simbólicos, inconscientes y arbitrarios, sobre los cuales descansa, tanto la autopercepción como la percepción del otro y del mundo; es decir, la construcción de realidad.

En otro ejercicio, se partió del uso cotidiano del lenguaje para referirse a atributos de las personas teniendo en cuenta el género. Se les pidió que explicitaran los significados que para ellos y ellas tenían esas expresiones y se escribieron en un cuadro.

\begin{tabular}{|l|l|l|l|}
\hline \multicolumn{1}{|c|}{$\begin{array}{c}\text { Palabra en } \\
\text { masculino }\end{array}$} & Connotación & \multicolumn{1}{|c|}{$\begin{array}{c}\text { Palabra en } \\
\text { femenino }\end{array}$} & Connotación \\
\hline perro & avispado & perra & prostituta \\
\hline zorro & astuto & zorra & prostituta \\
\hline $\begin{array}{l}\text { hombre } \\
\text { público }\end{array}$ & $\begin{array}{l}\text { persona } \\
\text { importante }\end{array}$ & mujer pública & prostituta \\
\hline
\end{tabular}


A continuación, se abrió la discusión preguntando por qué con el solo hecho de que la palabra pase de masculino a femenino hace que el significado cambie de manera tan radical e incluso se convierte en su opuesto. Concluyeron que la connotación positiva asociada a lo masculino y la negativa a lo femenino la habían aprendido de su mamá, de su papá y sus hermanos y hermanas; en la calle, en la televisión, en todas partes. A continuación se preguntó ¿¿si ustedes aprendieron eso de sus padres, de dónde creen que sus padres lo aprendieron? Con ello, se evidenció una estructura temporal e histórica de transmisión y reproducción de valores e ideas discriminadoras con respecto al género.

En el desarrollo de este proceso el sentido del ser "pobre", de "clase baja", del "sexo débil", deja de ser lo que era, el símbolo se fractura y la mirada cambia, se transforma. Desde este abordaje, sería interesante revisar los adjetivos con los que los docentes usualmente calificamos a los estudiantes, las connotaciones que tienen y los prejuicios, estereotipos y generalizaciones presentes allí.

Un ejemplo más. Se quiso explorar la representación social de "ladrón". Se pidió a los estudiantes que escribieran la palabra en el centro de una hoja y que alrededor de ella escribieran en un minuto, cinco cosas relacionadas con ella. Luego, se recogieron en el tablero las redes semánticas resultantes: sucio, feo, negro, mal vestido, barbado. ¡Aflora todo el caudal simbólico y las connotaciones que tiene! Se formula entonces una primera pregunta que lleva a relativizar los resultados: ¿entre las personas limpias, bonitas, blancas, bien vestidas y sin barba, no hay ladrones? Silencio, ojos abiertos y expectantes, labios a punto de decir algo que no acaba por salir, bloqueo, carcajadas, jinsigth! Luego viene una larga discusión en la que se ponen ejemplos y evidencias de lo errada y estereotipada que es la representación y de las fuentes y caminos que la han construido, y los intereses y ocultamientos que están tras de ella. En aras de la brevedad creo que los tres ejemplos presentados son suficientemente ilustrativos.

Es a partir de este enfoque como se han venido trabajando los conceptos y temáticas desarrolladas dentro de la clase de ciencias sociales. A lo largo del proceso se va desarrollando en los y las estudiantes suficiente habilidad para identificar y develar elementos simbólicos presentes en cada tema.

Paralelamente con este trabajo, se aborda el análisis de obras literarias y cinematográficas seleccionadas, que estén relacionadas con los temas tratados en clase y se ponen en común a través de conversatorios y cine foros, que nutren con nuevos elementos de análisis y enriquecen, tanto las discusiones desarrolladas, como la participación, la expresión oral en público y la producción de texto a través de la escritura de ensayos y su posterior lectura y discusión.

En cuanto a la evaluación de la experiencia, se ha realizado un seguimiento a través de un instrumento en el que cada periodo los y las estudiantes escriben, de manera anónima, los aciertos, desaciertos y aportes concretos que encontraron en el trabajo desarrollado en clase. Esto ha permitido una retroalimentación permanente, la posibilidad de restructuraciones y una valoración positiva de los logros alcanzados. La continuidad durante dos años con los mismos grupos de estudiantes ha permitido evaluar las transformaciones y avances logrados en cuanto a participación, construcción de pensamiento crítico y reflexivo, autoestima, autonomía, empoderamiento, niveles de lectura, análisis y producción de texto e interés y compromiso con el trabajo desarrollado en clase.

La connotación positiva asociada a lo masculino y la negativa a lo femenino la habían aprendido de su mamá, de su papá y sus hermanos y hermanas; en la calle, en la televisión, en todas partes. 
De la aplicación de este instrumento, a finales de noviembre de 2013, con 72 estudiantes de grado 11 y su sistematización se pueden encontrar indicios de que la propuesta está logrando el impacto esperado. Tomando el conjunto de estas evaluaciones como corpus se destacan las siguientes locuciones y frecuencias en orden de importancia: desarrollar pensamiento crítico, mirar más allá, abrir la mente (75\%); desarrollar el placer y el hábito de la lectura (56\%); aprender a ver desde diferentes perspectivas (26\%); perder miedos (18\%); conocerme a mí mismo (14\%); confiar, creer y amarme a mí mismo (14\%); ser una persona más abierta $(11 \%)$; cuestionarme $(10 \%)$; cambiar mi modo de vida ( $8 \%)$; ganar más autonomía (7\%); entender la importancia de hacerme escuchar y escuchar a los otros (7\%); reflexionar sobre uno y la sociedad (6\%); dejar las cosas que nos atan $(6 \%)$.

Aunque esto no constituye una evaluación rigurosa, ninguna la es, sí da indicios de los logros y del impacto que la propuesta puede estar alcanzando.

Esta propuesta fue implementada en el Liceo Nacional Antonia Santos, jornada de la mañana, con estudiantes de los grados $8^{\circ}$ y $10^{\circ}$ durante 2012 y con los grados $9^{\circ}$ y 11 durante 2013, desde la clase de ciencias sociales, filosofía, ciencias políticas y economía. Actualmente, (2014) continúa implementándose con estudiantes de los grados $10^{\circ}$ y $11^{\circ}$.

\section{Se cierra el telón}

Afirma Michel Foucault que "el conocimiento es siempre una determinada relación estratégica en la que el hombre está situado" (Foucault, M. 1999, p. 179). En ese sentido podría afirmarse que la implementación de la propuesta logró en buena medida situar a los y las estudiantes, en un lugar que percibían como "distinto" y que hizo posible desarrollar interés, participa- ción, compromiso, capacidad de escucha y debates acalorados, incluso con fuertes componentes afectivos. Otro aspecto para destacar es el aumento de las expectativas de los estudiantes para ingresar a las universidades públicas que fue un poco bajo en el 2012 y aumentó significativamente en los y las estudiantes graduados en el 2013 y 2014, aunque obviamente no se puede atribuir exclusivamente al desarrollo de esta propuesta, sino a la suma del trabajo del equipo docente de la institución.

Quizás es tan importante lo que hay que aprender, como lo que hay que desaprender y para eso debería trabajar el sistema educativo, debería convertirse en un sistema de des-aprendizaje, de develamiento, de deconstrucción de universos simbólicos subalternos, aplastantes, empobrecedores, devaluadores, inmovilizadores, inhibidores, negadores de la autonomía y de la búsqueda de libertad individual y colectiva. Pero el sistema educativo está apasionadamente dedicado a la reproducción de esos universos simbólicos y, lo que es peor, dedicado sin siquiera saberlo. La inconciencia es una condición fundamental para que la reproducción del orden social funcione.

Quizás, desterrando la violencia simbólica presente en el contexto educativo, podríamos tomar cualquier clase, para hacer un trabajo creativo, apasionado, comprometido, en el que las temáticas, las formas de trabajo, los intereses, sean compartidos entre estudiantes y docentes. Podríamos tomar el aula como laboratorio, como espacio de encuentro interhumano, lúdico, afectivo, armónico, dialógico, cuestionador, crítico, reflexivo, es decir, como un verdadero espacio de formación colectiva y humana, donde palpite la vida, la risa, la palabra, las preguntas, las dudas, los encuentros y desencuentros, el conflicto y nuevas formas de tramitarlo, porque finalmente es el conflicto el que nos hace crecer y también porque otro mundo es posible, un mundo una vez más, reencantado.

\section{Referencias}

Abric, J.C. (2001). Prácticas sociales y representaciones. México D.F.: Ediciones Coyoacán.

Bourdieu, P. y J.C. Passeron, J. C. (1972). La reproducción. Elementos para una teoría del sistema de enseñanza. Barcelona: Editorial Popular.

Foucault, M. (1999). Estrategias de poder. Barcelona: Paidós. 


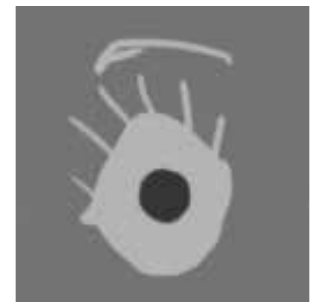

